\title{
Taiwan's View of the Trump Administration
}

Edition 7, 2021

Melissa Conley Tyler

DOI: $10.37839 / M A R 2652-550 X 7.2$

President Trump was not popular across Asia. From Japan and South Korea to Southeast Asia, he had a negative effect on perceptions of the United States. In Australia, there was a palpable sense of relief at his departure so that normalcy could return.

But Taiwan was staunchly pro-Trump. Opinion polling shows that-unlike other parts of Asia and Europe-the majority supported Trump's re-election. After the vote, there were pro-Trump rallies and thousands of Taiwanese Facebook pages were blocked from sharing claims of a stolen election.

After the election, only six percent of voters for the governing Democratic Progressive Party thought US-Taiwan relations would get better under Biden.

To explain Trump's popularity, we need to understand what Taiwan wants from the US and what Trump offered.

\section{Taiwan's fears}

Taiwan's history and status, means it has a unique relationship with the US.

Its current situation is a relic of the 1940s when the Nationalists and Communists fought for control of China. The Nationalists lost the civil war and retreated to Taiwan. 
Over the last 72 years, Taiwan has developed its own identity as a distinct place. Opinion polling in Taiwan shows that only a minority support unification with the People's Republic of China (PRC), even under ideal economic, social and political conditions. The majority would prefer independence, with two-thirds supporting this if Taiwan could maintain peaceful relations with the PRC and almost 50 per cent still thinking Taiwan should declare independence even if this would lead to an attack.

Taiwan's overriding fear is of abandonment. Without US arms sales-and the deterrent effect of the possibility that the US would enter a military conflict-Taiwan's strategic options would drastically narrow.

While some are worried about the potential for escalation, most are more anxious about the PRC trying to turn Taiwan into the next Hong Kong. They are concerned about PRC use of grey zone tactics like a trade embargo or naval blockade. They worry about the PRC being able slowly to cut Taiwan off, wear down Taiwan's resolve and make it go down quietly. 'The Taiwanese public need the confidence that they have allies and friends that support them so that they don't give in to Chinese intimidation.' The question on their minds is, who will be there to help? Taiwanese feel their isolation acutely.

So, Taiwan wants a US that is committed to stability in the region and is willing to deter China's aggressive action: to show presence and resolve and to sell weapons to help Taiwan maintain the capability to protect itself. They want 'concrete measures supporting Taiwan, not just beautiful words'.

Seen from this perspective, the US has been somewhat cagey, and certainly well short of full support. The US recognises the PRC, switching its diplomatic recognition in 1979. While the US Congress passed the Taiwan Relations Act-which states that it is US policy that the future of Taiwan will be determined by peaceful means-this isn't a treaty obligation, so there's some ambiguity about what the US would do if Taiwan were attacked. The aim of the ambiguity has been that Taiwan won't be tempted to declare independence (since it's not absolutely sure that the US 
will support it), while the PRC will be deterred from resolving the situation by force (since it's not absolutely sure that the US won't). This designed to stop both Taiwan and the PRC from going too far.

Taiwan saw the Obama Administration as a continuation of previous policy: carefully crafted diplomatic talk, cautious dealing and limits on official contact. To give a sense of what this means in practice consider the following: Taiwan's president can't just call the US president; there is limited contact between diplomatic officials; Taiwan is not involved in joint military exercises; and it has no free trade agreement with the US. The relationship is well short of what any of the US' allies and partners in the region would take for granted.

\section{Giving Taiwan hope}

Trump burst into this with his lack of concern for diplomatic niceties. He was unexpected from the start, when as president-elect he took a congratulatory phone call from Taiwan's President Tsai Ing-wen. This was dramatic and hugely symbolic, breaking with protocol since 1979. It was seen as a signal that Trump was prepared to stand up to China.

Throughout his presidency, Trump was viewed as being strong on China. This could have gone the other way: as a businessman with family dealings in China, he might have been seen as someone who might sell Taiwan out with a 'big deal'. But instead he was seen as 'telling it like it is, telling China where to go' in both his trade war and provocative statements on China. For those deeply concerned by the PRC threat, Trump's willingness to give China a hard time was welcomed: 'if someone can make Xi look embarrassed, he's your friend.'

In the public's perception, Trump was viewed as someone who really cared about Taiwan and was ready to go all the way for Taiwan, strange as this may seem given that his campaign explicitly advocated putting America first. 'People feel, finally, the 
US is not restraining Taiwan but seeing China with the same eyes we've always seen China, as a threat to regional order.' His resolve to stand up to China gave Taiwanese people confidence.

And it wasn't just his belligerent style. There was also substance.

There were very significant arms sales from 2017-2020, by contrast with the Obama Administration that delayed and cancelled weapon sales. In just two years of Trump's presidency, Taiwan purchased more arms that in the previous decade, helping normalise the process of arms sales. Trump was seen as focusing on the security aspects of Taiwan's situation more than previous administrations: supporting Taiwan against China and taking US obligations around maintaining infrastructure and war-readiness seriously.

Trump increased the US military commitment to Taiwan, supporting US military aircraft operating in Taiwan's air identification zone and regular patrols by US military vessels. When China was being particularly aggressive, Trump would be equally aggressive. Taiwanese greatly appreciated Trump's willingness to 'put planes out there' to do something concrete about Chinese pressure on Taiwan as well as its broader Free and Open Indo-Pacific (FOIP) concept.

Also important for diplomatically-isolated Taiwan was the improved contact between officials. The American Institute in Taiwan was redeveloped to be more like an embassy, including more military presence. Bilateral initiatives included the establishment of a US-Taiwan Economic Prosperity Partnership Dialogue, a USTaiwan Education Initiative, US-Taiwan Consultations on Democratic Governance in the Indo-Pacific Region and Taiwan signing up to an infrastructure finance initiative. Trump's presidency was marked by increased official contact, culminating in the visit of Secretary of Health Alex Azar, the highest-level Cabinet official to hold talks in Taipei since 1979. The US was also willing to use its pressure to help Taiwan maintain the small group of countries that recognise it diplomatically.

During the Trump Administration, the Global Cooperation and Training Framework 
(GCTF) was broadened not just for bilateral relations but to increase Taiwan's international space. The GCTF's mission is to provide a platform to harness Taiwan's strengths and expertise to address global issues. During the Trump Administration it held 24 international workshops involving more than 1,000 officials and experts on themes like public health, women's empowerment, law enforcement, energy, cybersecurity and disaster relief. This is greatly appreciated by Taiwan as helping it contribute to international discussions. It also enables Taiwan to promote its foreign policy messages, such as allowing Taiwanese experts to talk to other countries about Chinese infiltration, countering disinformation and religious freedom.

The only area in which there was less progress was on a bilateral free trade agreement, with no talks on the proposed Trade and Investment Framework Agreement since 2016. Despite support among figures in the Trump Administration this did not progress, apparently due to opposition from the US Trade Representative. The main focus of the administration was on the China trade deal, with concern that an economic agreement with Taiwan might have derailed this.

An important element in the Trump Administration policy on Taiwan was the role of Trump's inner circle, with his Cabinet including many who were considered longterm supporters of Taiwan. In the early days of the administration, this gave a reliable channel to a somewhat chaotic White House. It meant that there were people willing to discuss areas that had previously been forbidden. Trump himself may have just been using Taiwan as a button he could press with China- 'as a way to poke China in the eye'-but some in the inner circle had wider aims. From the Vice-President down there were people around him who were viewed as friends of Taiwan, nudging him in the right direction and prompting him to mention Taiwan.

Another factor was the role of Congress, which is an important element in USTaiwan relations. During the Trump Administration several laws were passed to help Taiwan promote its visibility in the US and internationally including the Taiwan Travel Act (2018), the Taiwan Allies International Protection and Enhancement 
Initiative (TAIPEI) Act (2019) and Taiwan Assurance Act (2020). Trump didn't just not veto these pieces of legislation, he went out of his way to sign them into law.

The Trump Administration's support of Taiwan continued right to the end with the announcement just 11 days before Biden's inauguration that all restrictions on official contact with Taiwan were null and void. It was very Trumpian: a big announcement that surprised, but without clarity on what it meant or how it would be implemented in practice.

It typified an unconventional approach that opened possibilities and made breakthroughs, that tested limits and questioned constraints. Exciting, but unpredictable.

\section{Election 2020}

With such a positive reaction to the Trump Administration-both in style and substance-it is not surprising that there were strong pro-Trump views before the US Presidential Election, both among Taiwan's government and the general public. In some circles, not being pro-Trump might mean you were accused of being a Chinese sympathiser.

While the Tsai Government was careful to state that Taiwan-US relations would remain strong regardless of who won the election, it was viewed as leaning proTrump. This political alignment may appear somewhat strange, with the governing party-the socially-progressive Democratic Progressive Party-presumably doing some mental compartmentalising of its policy differences on social issues. The opposition Kuomintang (KMT) was more sceptical about the narrative that Trump represented some sort of fundamental change in the US commitment to Taiwan-and privately may have expressed concerns about Trump encouraging wishful thinking in Taiwan about how much it could rely on the US.

In the eyes of the public, Trump was viewed as someone that would support Taiwan 
without reserve. The more clear-eyed might admit that Trump was not fighting for Taiwan; but with Trump so hell-bent on being anti-China this would positive for Taiwan, with Taiwan benefiting from 'competition between two giants'.

This meant that November 2020 was the most-followed US election ever in Taiwan, with an outpouring of support for Trump. Taiwanese report that they are one of only two places, with Israel, where there was majority support for Trump's re-election. And the common belief was that Trump would win.

Post-election there was real anxiety and worry. People had got used to Trump's tough rhetoric and thought Biden would be more timid. At the extreme, conspiracy theories circulated about Hunter Biden's business dealings and Biden being compromised by Beijing. People who had become emotionally invested continued to contest the validity of the election result.

Even among the level-headed, there were fears that Biden would be soft on China. His campaign statements were interpreted as cautious, with concerns that he would be 'Obama 2.0', having served as Obama's Vice President and being expected to hire many Obama-era people. It was thought that with so many problems at home, he would try to de-escalate tensions with China to Taiwan's detriment.

In fact, Biden's first 100 days have reassured many of these concerns, starting with the invitation to Taiwan's diplomatic representative to attend his inauguration. For the most part, perceptions appear to be that the Biden Administration remains tough on China but is more professional and able to get things done. It is seen as a significant improvement over the Obama terms. The task for Taiwan now is to consolidate the gains of recent years with a more predictable administration.

But while much of Taiwan's establishment is busy executing a pragmatic 180 degree turn towards Biden, this does not alter their affection towards Trump. He'll be remembered as someone who shook up the bureaucratic system and forced a rethink on the terms of the relationship; as someone who pushed against established views and opened a window for US-Taiwan relations. As a 'battering ram'; as having a 
'steroid effect'; and as someone who 'kickstarted' an improvement in relations.

So, in Taiwanese eyes, it looks like the Trump years will be remembered as an opening-rough and somewhat unpredictable-which was consolidated during the Biden years. They are likely to remain genuinely grateful to Trump. 'Emotionally in our hearts, we always appreciate what Trump has done for us, he deserves that response.'

For countries inclined to see the Trump years as a 'blip' with Biden bringing the US back to normal in its relations in Asia, it's worth understanding Taiwan's quite different point of view.

Melissa Conley Tyler is in Taiwan as a visiting fellow at the Institute for National Defense and Security Research, funded by a Taiwan Ministry of Foreign Affairs fellowship. This article is a synthesis of views gathered from 23 anonymous interviews in Taiwan, including with inner circle figures and politicians. 